\title{
AS REFORMAS EDUCACIONAIS DOS ANOS 90 E OS IMPACTOS NA GESTÃO DA EDUCAÇÃO BRASILEIRA: CONCEPÇÕES E PRINCÍPIOS
}

\author{
EDUCATIONAL REFORMS OF THE 90s AND THE IMPACTS IN MANAGEMENT \\ OF THE BRAZILIAN EDUCATIONAL: CONCEPTIONS AND PRINCIPLES
}

\author{
G. F. A. M. AZEVEDO ${ }^{1, *}$ \\ ${ }^{1}$ Instituto Federal de Educação, Ciência e Tecnologia do Maranhão, Coordenação de Atividades Técnico \\ Pedagógica, Brasil
}

ARTICLE INFO

Article history:

Received 2018-07-11

Accepted 2018-12-20

Available online 2018-12-21

${ }^{*}$ Autor correspondente:

E-mail: gisafamaral78@gmail.com

\section{Palavras-chave: Gestão Democrática. Políticas} Educacionais. Reformas Educacionais.

Keywords: Democratic Management. Educational Policies. Educational Reforms.

RESUMO. As grandes transformações sociais, científicas e tecnológicas impactadas pela mundialização do capital, apoiada na reestruturação produtiva, afetaram diretamente o campo educacional exigindo um novo perfil de profissional da educação, que atendesse as determinações impostas pelo capital no sentido de acelerar o desenvolvimento da economia e enquadrá-la ao modelo empresarial de cunho privatista. Desta forma, a escola, passa a cumprir um importante papel nesse contexto, tendo como um de seus objetivos principais a formação de força de trabalho que venha atender ao mercado cada vez mais exigente e segregador. Logo, neste artigo, tem-se como objetivo principal analisar o contexto da mundialização do capital, e seus impactos nas reformas educacionais propostas pelos organismos internacionais, cujas recomendações propõem modelos gerencialistas para a gestão dos sistemas e das escolas pautados na eficiência e na eficácia dos processos educacionais. Enfoca-se o princípio da gestão democrática disposto na Constituição Federal de 1988 e na LDBEN 9.394/96 que tem como maior desafio a sua consolidação no contexto escolar, através de práticas que incentivem a participação como ato político e democrático.

\begin{abstract}
The great social, scientific and technological transformations impacted by the globalization of capital, supported by the productive restructuring, directly affected the educational field, demanding a new profile of education professionals, which met the determinations imposed by capital in order to accelerate the development of the economy and the framework to the privatized business model. In this way, the school plays an important role in this context, having as one of its main objectives the formation of a workforce that will meet the increasingly demanding and segregating market. Therefore, the main objective of this article is to analyze the context of the globalization of capital and its impact on educational reforms proposed by international organisms, whose recommendations propose managerialism models for the management of the systems and of schools based on the efficiency and effectiveness of educational processes. We emphasize the principle of democratic management established in the Federal Constitution of 1988 and in LDBEN 9,394/96 that has as its greatest challenge the your consolidation in the school context, through practices that encourage participation as a political and democratic act.
\end{abstract}




\section{Introdução}

Estudar educação e compreendê-la não é algo simples, mas complexo e requer estabelecer relações com aspectos econômicos, sociais, culturais, políticos, históricos e jurídicos que influenciam na determinação das políticas educacionais, pois estas não são neutras e estão relacionadas com a totalidade dos processos sociais. "A história nos ensina que a reconstrução de um caminho implica um processo de desconstrução que não apaga as marcas, ocultas ou manifestas, das construções anteriores" (SANDER, 1995, p. 13). Logo, compreende-se que a educação é um processo histórico de construções e desconstruções, fruto de determinantes externos e internos, sendo constituída e constituindo quem dela se utiliza, buscando a transformação social ou a reprodução de interesses particulares e manutenção de um determinado status quo.

A problematização desse estudo compreende que a gestão escolar não se consolida no vazio, desta forma relaciona-se no tempo, no espaço em que é construída. Para analisála é necessário compreender o contexto histórico, econômico e social onde se efetiva, pois a mesma é concebida para atender as concepções e interesses de grupos sociais diversos. Paro (2010) corrobora com essa questão quando destaca que a educação não acontece dissociada do contexto histórico e social presente, pois é resultado de uma "longa evolução histórica, e traz a marca das contradições sociais e dos interesses políticos em jogo na sociedade" (p. 24).

Frigotto (2010, p. 27) também ressalta que:

A educação, quando apreendida no plano das determinações e relações sociais e, portanto, ela mesma constituída e constituinte destas relações, apresenta-se historicamente como campo da disputa hegemônica. Esta disputa dá-se na perspectiva de articular as concepções, a organização dos processos e dos conteúdos educativos na escola e, mais amplamente, nas diferentes esferas da vida social, aos interesses de classe.

Nesse contexto compreendemos que o Brasil está organizado sob os moldes do sistema capitalista, resultante da divisão social de classes, onde a classe dominante detentora do capital e dos meios de produção, se apropria da força de trabalho das classes dominadas. Esta dominação não é exercida de forma direta, mas consolidada através de estruturas jurídicas, políticas, sociais e culturais, o que exercem influência na realidade educacional do país.

O capitalismo em sua fase atual que rompe barreiras comerciais através da globalização e da mundialização do capital vem causando discussões e contradições sob o 
papel da atuação do Estado na sociedade, onde este pode atuar e como pode interferir nas decisões econômicas, nas políticas públicas entre elas nas políticas educacionais.

As políticas educacionais do Brasil passaram por grandes transformações na década de 90 do século passado, impactadas pela globalização e pela reestruturação produtiva, que afetaram a concepção de educação que, deveria voltar-se para preparação da força de trabalho para atender ao mercado em constante instabilidade. Sobre reestruturação produtiva, Rosar (2008, p. 160) enfatiza que

[...] durante os últimos anos da década de 1980 e os anos 1990, difundiu-se uma vertente da sociologia que colocou no centro do debate educacional a necessidade de adaptação da escola ao processo de reestruturação produtiva que parecia estar ocorrendo no Brasil, tal como acontecera nos países hegemônicos. Os conceitos de qualidade total, de descentralização, de autonomia e de avaliação, articulados com a perspectiva do toyotismo, apresentaram-se no discurso oficial do MEC e foram amplamente reproduzidos nos diversos espaços de atuação dos educadores submetidos a um processo de qualificação programada conforme os paradigmas oficiais.

Assim, as reformas educacionais ocorridas no final do século $X X$ e que continuam sendo desenvolvidas no século XXI são resultados das transformações sofridas pelo capitalismo a nível mundial sob as orientações do paradigma neoliberal.

Foram propostas reformas para a educação da América Latina, para que a mesma se tornasse mais flexível, competitiva com objetivo de adaptar os países emergentes ao capital globalizado.

Sobre globalização, Chesnais (1996, p. 25) enfatiza que

a globalização é quase invariavelmente apresentada como um processo benéfico e necessário. Os relatórios oficiais admitem que a globalização decerto tem alguns inconvenientes, acompanhados de vantagens que têm dificuldade em definir. Mesmo assim, é preciso que a sociedade se adapte (esta é a palavra-chave, que hoje vale como palavra-de-ordem) às novas exigências e obrigações, e sobretudo que descarte qualquer ideia de procurar orientar, dominar, controlar, canalizar esse novo processo. Com efeito, a globalização é a expressão das forças de mercado, por fim liberadas (pelo menos parcialmente, pois a grande tarefa da liberalização está longe de concluída) dos entraves nefastos erguidos durante meio século. De resto, para os turiferários da globalização, a necessária adaptação pressupõe que a liberalização e a desregulamentação sejam levadas a cabo, que as empresas tenham absoluta liberdade de movimentos e que todos os campos da vida social, sem exceção, sejam submetidos à valorização do capital privado.

Nesse contexto destaca-se os organismos internacionais entre eles o Banco Mundial (BM) que foi um dos principais financiadores dessas reformas, além de financiá-las também prestava assessoria aos países. Como bem destacou Torres (2009, p. 126):

O Banco Mundial não apresenta ideias isoladas, mas uma proposta articulada, uma ideologia e um pacote de medidas para melhorar o acesso, a equidade e a qualidade dos sistemas escolares, particularmente do ensino de primeiro grau, nos países em desenvolvimento. Embora se reconheça 
que cada país e cada situação concreta requerem especificidade, trata-se de fato de um " pacote" de reforma proposto aos países em desenvolvimento que abrange um amplo conjunto de aspectos vinculados à educação, das macropolíticas até a sala de aula.

Com base no pensamento de Torres compreendemos que o Banco Mundial se preocupou com a padronização de um modelo educativo que proporcionasse o acesso, a qualidade dos sistemas educacionais, mas que provocou exatamente o contrário, pois tem reforçado condições específicas para que a péssima qualidade no ensino e a desigualdade dentro das instituições escolares se perpetuem. Tudo contribuía para que a educação se delineasse de acordo com as novas exigências dos ajustes comandados pelo capitalismo a nível mundial. As principais recomendações desses organismos estavam subsidiadas em alguns princípios tais como descentralização, autonomia, participação, co-gestão envolvendo a comunidade escolar na gestão das políticas educacionais.

Neto e Rodriguez (2007, p. 14) fazem uma interessante reflexão sobre o tema quando ressaltam:

É nesse processo que se inserem as atuais reformas educacionais no continente latino-americano. Elas são resultados de políticas que, aparentemente, possuem perfil nacional, mas têm, de fato, uma base regional. As reformas ocorrem dentro de um determinado período histórico e são sustentadas por sistemas de ideias comuns a uma mesma região e circulam em várias áreas e em algumas mais perceptíveis (como atualmente na economia). Entretanto, é na cultura, principalmente na educação, que sua permeabilidade e sua circulação tornam-se mais evidentes no processo de regionalização. A lógica de construir orientações regionais materializa-se na formulação de políticas com objetivos e estratégias comuns para todo o continente latino-americano.

Um fato convém ser destacado, que é exatamente de estabelecer orientações comuns podemos assim denominar de orientações homogêneas, padronizadas da educação para todos os países do continente. Observa-se nessa padronização a criação de avaliações classificatórias por desempenho, tanto de alunos como de professores, currículos que atendam às necessidades de formação para o mercado de trabalho, e novas formas de gestão das escolas, alicerçadas na concepção gerencialista, pois muitos são os impactos que essa nova configuração internacional do capitalismo trouxe para a pedagogia e especificamente para a gestão das escolas.

Corroborando com as considerações elencadas acima, Sander (1995, p. 128) destaca que:

O certo é que no campo da administração da educação, os modelos tradicionais e as antigas hipóteses enraizadas nas teorias tecnoburocráticas e funcionalistas de organização e gestão não oferecem as soluções requeridas num mundo em vertiginoso processo de mudança para novos padrões de desenvolvimento e novas formas de organização social e educacional. A nova realidade nos coloca diante de um desafio conceitual e 
praxiológico de enormes proporções. Para enfrentá-lo é necessário concentrar esforços visando à criação de formas de organização e gestão da educação que favoreça a inserção da escola e da universidade no contexto global da sociedade moderna em transformação.

Se o objetivo é compreender a realidade, não para nos adaptarmos a ela de maneira passiva e sim discuti-la de forma crítica para então atuarmos de maneira diferente daquela que nos são impostas pelo sistema capitalista, pois não basta adaptar é preciso que tanto a escola como a universidade acompanhem as constantes transformações da sociedade, propondo, participando e envolvendo-se com a construção de novas relações sociais. Para isso precisamos compreender outras formas de gestão para além do capital, com destaque para uma participação plena dos nossos alunos, através de uma prática que nos proporcione um ambiente de construção coletiva com autonomia para promover qualidade no processo de ensino aprendizagem para além de uma formação para atender a um mercado que objetive sempre produzir em busca de lucro, é preciso educar para a cidadania. Esse é nosso papel enquanto intelectuais e pesquisadores que lutam pela transformação social e por uma escola mais justa e democrática.

Deve-se ter em mente, que muitos são os embates em torno de se efetivar novas teorias para os estudos da gestão da educação numa perspectiva que respeite as condições econômica, cultural, social de cada realidade e país. Na maioria das vezes os modelos são impostos dos países desenvolvidos, para serem implantados nos países emergentes, o que se pode chamar de um tipo de modernização que não foge ao conservador.

Desta forma é necessário transpor as concepções tradicionais da educação e de reprodução social e cultural. Novas descobertas e superação teórica se concretizarão através de novos estudos e pesquisas levando-se em consideração a realidade e as necessidades das pessoas que constroem um determinado contexto. Podemos destacar que para efetivação de novas propostas na gestão dos sistemas educacionais, a participação dos cidadãos é condição sine qua non para sua concretização. Acreditamos que o grande desafio está em pensar formas de compreender a educação e a gestão para que respondam as necessidades do nosso país sem esquecer o contexto internacional das reformas educacionais trazidas aos países da América Latina.

Sobre a questão da categoria participação acima evidenciada, Paro (2005, p.16) destaca que:

a gestão democrática deve implicar necessariamente a participação da comunidade, parece faltar ainda uma maior precisão do conceito de participação. A esse respeito, quando uso esse termo, estou preocupado, no limite, com a participação nas decisões. Isto não elimina, obviamente, a participação na execução; mas também não a tem como fim e sim como meio, quando necessário, para a participação propriamente dita, que é partilha do poder, a participação na tomada de decisões. É importante ter sempre presente este aspecto para que não se torne a participação na execução como fim em si mesmo, quer como sucedâneo da participação nas decisões, quer como maneira de escamotear a ausência desta última 
no processo.

As reformas educacionais que foram impostas no decorrer da década de 90 na América Latina e especificamente no Brasil tinham como principais fundamentos a descentralização, a autonomia escolar, a co-gestão da comunidade dentre outros aspectos que nos levam a compreender que essas orientações estão diretamente articuladas com o projeto de educação neoliberal, objetivando um novo paradigma de organização do Estado e do setor público para atender as exigências do capital. A educação obteve um destaque nessas reformas pois era entendida como chave para o progresso social, tendo sido submetida a avaliações externas classificatórias, com intuito de medir resultados baseados em padrões de qualidade estabelecidos como mínimos para o ensino. Enfim o Brasil acompanhou as reformas propostas a nível mundial através de medidas descentralizantes e regulatórias.

A partir do século XX tem-se fortalecido no Brasil a gestão por resultados, na modernização dos processos educativos admitindo-se a gestão descentralizada e compartilhada através da participação dos usuários agora chamados de clientes, seguindo as determinações dos organismos internacionais.

Desta forma, Lopes e Castro (2012, p. 34) destacam que:

$\mathrm{Na}$ atualidade, pode-se dizer que convivem na escola diferentes modelos de gestão, mas é, no gerencialismo, que se apoiam os programas oficiais em implantação em todo o sistema nacional. O gerencialismo teoria administrativa decorrente da articulação entre participação e controle, que prevê, em seu arcabouço teórico, um conjunto de medidas aplicáveis desde a estrutura administrativa central até suas várias agências, passou a ser incorporado pelas empresas como modelo ideal de organização e gestão do trabalho e, posteriormente, foi utilizado pelas políticas públicas como o caminho para a modernização da administração pública, e, portanto, para a adequação às exigências contemporâneas.

Compreende-se a partir da citação acima que características de uma gestão pautada no gerencialismo, orientada pelos pilares do neoliberalismo se fazem presente dentro da escola, por meio do discurso da descentralização, da responsabilização de diretores e professores por possíveis fracassos e sucessos de ações tomadas, focalizando novas estratégias para o serviço público, com o objetivo de tornar a escola mais eficiente, ágil, competitiva e produtiva.

Observa-se que os objetivos neoliberais para a gestão da educação estão no sentido de propor a descentralização do sistema educacional brasileiro, sendo a municipalização do ensino, uma forma de descentralização, apresentando-se como indispensável aos novos ditames para administração escolar. É importante ressaltar que a descentralização esteve ligada tanto aos aspectos da democratização almejada pelas camadas populares quanto as estratégias neoliberais apoiadas pelo discurso da modernização. 
Com base no exposto acima, destacamos que as determinações sugeridas pelos órgãos centrais da educação brasileira, evidenciam uma concepção distorcida de gestão democrática através da gestão compartilhada, que enfatiza a busca de parcerias para resolver de modo superficial e imediato problemas e dificuldades encontradas na gestão e na escola, o que enfraquece a proposta de um projeto articulado de educação (Hora 2010).

\section{A Gestão Democrática na Constituição Federal de 1988 e na LDBEN 9.394/96.}

Os estudos sobre o tema da gestão democrática sempre foi um dos mais debatidos no âmbito da educação brasileira, abrangendo tanto a educação básica quanto a educação superior, dada a sua importância para a compreensão das instituições públicas de educação que proporcionem um ensino de qualidade social.

Utilizando o conceito de Demo (1996, p. 11) entendemos qualidade para a dimensão da intensidade.

Tem a ver com profundidade, perfeição, principalmente com participação e criação. Está mais para o ser do que para o ter. O termo aplica-se mais propriamente à ação humana, até o ponto de defini-lo como o toque humano na quantidade ou na realidade como tal. Isso se deve à sua ligação com intensidade. Com efeito, somente poderia ser intenso aquilo que tem a marca do homem, por ser questão de vivência, consciência, participação, cultura e arte. Podemos resumir no desafio de construir e participar. Assim somente o que é histórico pode ser qualitativo, no sentido dialético do saberfazer história, dentro da unidade de contrários. Ser sujeito histórico, não massa de manobra, objeto de influência externa, sequela natural.

Logo a concepção e a prática da gestão escolar democrática, deve ser uma preocupação das políticas educacionais, não apenas no plano da teoria, mas na sua efetivação dentro e fora do ambiente escolar, políticas essas voltadas para a emancipação do homem e não para sua alienação, que garantam uma participação como ato político.

Na década de 1980 houveram muitos movimentos sociais no país que lutaram em prol de uma redemocratização política. Nesse contexto, as discussões e debates em torno da gestão democrática tomaram força no campo educacional, os sujeitos envolvidos com o processo educativo sentiam necessidade de participar das decisões por meio da descentralização das políticas educacionais. A grande questão era construir uma escola que atendessem a todos os cidadãos com uma educação de qualidade.

Essas reflexões estão apoiadas nas orientações normativas da Carta Magna de 1988, art. 206, Inc. VI, esta ressalta que o ensino será ministrado com base no princípio da "gestão democrática do ensino público, na forma da lei"; além do que concerne o texto da Lei ํㅜ 9.394/96, que estabelece as Diretrizes e Bases da Educação Nacional em seu art. 3ㅜ, Inc. VIII expressa a forma de "gestão democrática do ensino público, na forma desta Lei e da legislação dos sistemas de ensino" reiterando nos arts. 14 e 56 o princípio constitucional 
da gestão democrática da educação recomendando a instituição dos conselhos escolares e a construção coletiva do projeto político pedagógico, neste último, enfatizando as instituições públicas de educação superior.

O princípio da gestão democrática do ensino público, que foi assegurado pela Constituição Federal de 1988 e com a Lei 9.394/96 (Lei de Diretrizes e Bases da Educação Nacional - LDBEN), foi um grande marco na construção de uma gestão mais democrática que respondesse às aspirações dos movimentos de educadores que lutavam por uma participação mais ampla nas decisões das políticas educacionais e da gestão dos sistemas e das escolas. Visando introduzir no âmbito da educação um novo tipo de gestão, fundamentado nos pilares da democracia, da autonomia, da participação, da coletividade, da descentralização, opondo-se às práticas tradicionais, burocráticas e centralizadoras que vinham conduzindo o cenário educacional do período militar.

Desta forma compreende-se que a gestão democrática é um princípio legal e que tem tomado espaço nas produções acadêmicas, de reflexão crítica, por parte de grandes intelectuais no Brasil e no mundo, pois esse entendimento busca dar clareza a visão teleológica da educação. Teleológica no sentido etimológico da palavra telos, que no dizer de Oliveira (2004, p.7) "é palavra grega que significa fim, escopo, que se refere à finalidade última". Dessa forma, identificamos buscar pela finalidade da educação, ou seja, a razão para que esta foi criada, assim, analisando e discutindo sobre o tipo de sociedade e de profissionais que almejamos formar e, mais especificamente, que tipo de escola e de homem buscamos conceituar, homem aqui compreendido como ser humano integral, pensante, atuante e construtor da sua realidade histórico-social. Sob este prisma a educação não deve estar limitada somente à preparação de força de trabalho qualificada, e nem deve ser compreendida de forma descontextualizada. Nessa acepção, faz-se mister ressaltar o que é dito por Veiga (2006, p. 48):

A educação é compromisso ético dos brasileiros para com os outros brasileiros. Compromisso ético e não econômico. A produção deve crescer sim, mas com objetivos sociais. É certo que a educação do povo traz também benefícios econômicos, mas o objetivo é a dignidade.

Assim, a educação deve ser integral, e ainda, deve está fundamentada em alicerces da transformação social, da construção de um mundo melhor e de um homem mais humano. Neste sentido, Frigotto (et al, 2005, p. 85) entende que:

A ideia de formação integrada sugere superar o ser humano dividido historicamente pela divisão social do trabalho entre a ação de executar e a ação de pensar, dirigir ou planejar. Trata-se de superar a redução da preparação para o trabalho ao seu aspecto operacional, simplificado, escoimado dos conhecimentos que estão na sua gênese cientificotecnológica e na sua apropriação histórico-social, formação humana, o que se busca é garantir ao adolescente, ao jovem e ao adulto trabalhador o 
direito de uma formação completa para a leitura do mundo e para atuação como cidadão pertencente a um país, integrado dignamente na sua sociedade política. Formação que, neste sentido, supõe a compreensão das relações sociais subjacentes a todos os fenômenos.

Nesta perspectiva, o trabalho do gestor escolar ocupa um panorama de mudança, de transformação, de comprometimento, de efetivação de uma escola participativa, autônoma, democrática e descentralizadora, que preze pelo respeito aos profissionais e alunos, onde o Projeto Político Pedagógico (PPP) possa ser construído por todos e reflita as necessidades, a identidade da escola e os objetivos a serem alcançados em um constante processo de reflexão dialógica, em que a práxis pedagógica aconteça na ação-reflexão-ação, onde o conselho escolar possa ser um espaço para discussões coletivas que rompam com práticas centralizadoras enraizadas durante anos dentro das nossas escolas públicas. Discutir esses conceitos é algo relevante para compreensão do papel da escola em nossos dias, assim como entender a importância que os atores, especificamente, o gestor escolar, ocupa nesse cenário.

No entender de Veiga (2006, p. 14)

O Projeto Político Pedagógico é a construção do significado das palavras que o compõe, ou seja: projeto vem do latim projectu, particípio passado do verbo projicere, que significa lançar para adiante; político no sentido de ter compromisso com a formação do cidadão para um tipo de sociedade; pedagógico no sentido de definir as ações educativas e as características necessárias à escola e de sua intencionalidade. Portanto, o Projeto Político Pedagógico se constitui em processo democrático de decisões, buscando a eliminação das relações competitivas, autoritárias e arbitrárias, e instaurando a relação de cooperação nos níveis da organização da escola e da sala de aula, incluindo a relação com o contexto social imediato, portanto, busca a organização do trabalho pedagógico em sua globalidade.

Tal afirmação nos permite inferir que projeto significa olhar adiante, olhar para frente, projetar. Ao pensarmos na organização das nossas escolas projetamos ações, pensamos na realidade que temos e como podemos melhorá-la, isso ao nosso vê pressupõe quebras de uma situação presente para ir em busca de novas perspectivas de futuro. Embasada nessa concepção que o projeto político pedagógico deve ser pensado, não como algo a ser construído e logo em seguida esquecido ou arquivado, ou simplesmente feito para atender as exigências dos sistemas educacionais, secretarias ou órgãos centrais como mais uma tarefa burocrática que a escola obrigatoriamente deverá cumprir, ao contrário deve ser algo vivenciado por todos os sujeitos envolvidos com o processo educativo, que compreendemos como para além da sala de aula.

Sobre a construção coletiva do PPP, Lacerda (2004, p. 49) destaca que:

A construção do projeto político-pedagógico pela escola é a possibilidade de criação da sua identidade na busca dos seus rumos, devendo fundamentarse pelas relações democráticas entre os seus atores. Propicia a participação permanente na reflexão e discussão dos problemas da escola, frente à intencionalidade do ato educativo. Isso significa resgatar o papel da escola, 
como lugar de reflexão da ação, de debate e do diálogo coletivo.

Nesse contexto, o educador precisa pensar sobre o processo educacional, sentindose parte dele, a participação no sentido amplo da palavra, a discussão coletiva dos problemas da escola, a gestão democrática através do debate e do diálogo coletivo, são algumas questões que contribuem para a concretização de um espaço de poder com identidade própria.

Desta forma, defendemos um modelo de gestão escolar democrático, contrário ao modelo gerencial imposto pelos organismos internacionais, que coisifica o homem. No entender de Vaz (2004, p.120), explicando a teoria de Marx, "coisificação (Verdinglinching, reification, réification) representa dois tipos de alienação: a espiritual, sendo a deficiência de ser que sobrevém ao homem por não alcançar sua auto-realização; e a social representada pelo domínio do produto sobre seu criador". Logo, almejamos uma gestão como forma de participação humana e de formação para a cidadania, pois é imprescindível inserir a concepção de gestão escolar apoiada na democracia como fonte para humanização e para a formação de uma sociedade mais justa e igualitária. Paro (2002, p. 2) destaca:

Preocupar-se com a prática administrativa de nossas escolas envolve ter
em conta a coerência entre meios e objetivos na realização da atividade
educativa. A educação, entendida como emancipação humana, precisa levar
em conta a condição de sujeito tanto de educandos quanto de educadores.
Daí que ela só pode realizar-se de forma democrática, o que significa que a
administração que Ihe dá sustentação deve ser necessariamente
democrática. Considerar as políticas educacionais em suas relações com a
prática da gestão escolar significa, portanto, levar em conta a
democratização da gestão de nossas escolas.

Nesse contexto, faz-se mais que necessário refletirmos sobre que tipo de educação almejamos diante do sistema capitalista. Esta educação e mais especificamente a escola está contribuindo para transformação social ou para perpetuar as condições impostas pelo capital? Que concepção de administração ou gestão escolar estamos desenvolvendo em nossas escolas? Certamente não iremos encontrar proposições prontas e acabadas, mas a reflexão sobre um tema de relevância para os estudos educacionais da nossa realidade maranhense que claro não está desvinculada da realidade brasileira, irá nos proporcionar boas discussões e aprendizagens.

Em contrapartida aos que defendem a consolidação de uma gestão democrática e participativa, estão políticas de governos que articulam a implantação de uma perspectiva gerencialista no âmbito educacional. Estas marcadas pelos princípios do neoliberalismo, por meio da reprodução de práticas mercantis no âmbito educacional.

Com base nas ideias de Castro (2007, p. 124)

O modelo gerencial para o serviço público foi importado da iniciativa 
privada, destacando-se a Grã-Bretanha como o laboratório das técnicas gerenciais aplicadas ao setor público. Outros países, como a Austrália e a Nova Zelândia, também implementaram reformas no setor público. No entanto, apesar das características comuns às experiências de reforma, não há um sentido unívoco, isto é, um só paradigma organizacional que guie todas as nações. A reforma gerencial caracteriza-se pela busca da eficiência, pela redução e pelo controle dos gastos e serviços públicos, bem como pela demanda de melhor qualidade e pela descentralização administrativa. Há preocupação com o produto em detrimento dos processos.

Ao contrário da perspectiva gerencial a concepção de gestão democrática por sua vez, traz o conceito de participação de modo amplo, tanto na tomada das decisões como na construção coletiva do Projeto Político Pedagógico. Com base em Castro (2007) podemos ressaltar que a democratização da gestão da educação almeja a participação de todos tanto na formulação, avaliação, fiscalização e execução das políticas educacionais. É necessário incluir toda comunidade escolar (pais, alunos, funcionários e professores) nas decisões, o que irá consequentemente refletir na qualidade da educação oferecida aos alunos. Por outro lado, considera-se um grande desafio a concretização da participação ampla em nossas escolas públicas, pois as relações de poder corporativas e clientelistas ainda são muito fortes, além da falta de cultura da participação da comunidade escolar dentre outras questões que dificultam sua concretização no espaço escolar.

\section{Considerações Finais}

A história política do Brasil não foi alicerçada em uma tradição de participação cidadã, as pessoas não foram educadas a se envolverem organizadamente em prol de lutas coletivas, pelo contrário esperam que o Estado ofereça serviços em seus benefícios, tal postura reflete na falta de participação consciente do povo brasileiro. É necessária mudança de postura, de valores para que os cidadãos possam participar das decisões, e isso não deve se restringir exclusivamente ao âmbito escolar, mas alcançando o âmbito macro da sociedade Uma escola pública forte e emancipada requer o desenvolvimento de uma cultura da participação que abranjam todos os seus níveis e segmentos. Não somos ingênuos de afirmar que esta é uma tarefa fácil, pelo contrário requer educadores que acreditem na emancipação humana, e que a educação pode e deve ser um dos caminhos para a transformação social que supere a lógica opressora do mercado, ou seja, é fundamental lutar por uma gestão escolar para além do capital.

Outra questão que não se pode deixar de explicitar, é que o princípio da gestão democrática é defendido sob diferentes perspectivas. No entanto essa defesa ocorre de formas diferenciadas, ou seja, antagônicas. De um lado, temos os defensores de uma democracia em favor de um projeto social mais sólido e comprometido com a construção de uma educação livre, emancipadora e de qualidade para todos; por outro, estão os 
defensores do paradigma neoliberal, onde a educação e a gestão escolar são formas de assegurar eficiência, eficácia e a produtividade do processo pedagógico. A escola passa a ser comparada a uma empresa, produtora de serviços educacionais.

Compreendemos que a escola não é apenas reprodutora de relações sociais verticalizadas e dominantes, é também local de resistência e enfrentamento. Sob essa ótica, ela procura ir além do aspecto tecnicista, quebrando com a velha separação entre pensar e executar, uma perspectiva fruto de uma administração clássica, centralizadora, que refletia a divisão social do trabalho dentro da instituição escolar que ainda nos dias atuais se perpetua através da dualidade educacional, com a separação entre ensino científico, propedêutico e ensino profissionalizante. Por conseguinte, o PPP ao ser tanto político quanto pedagógico deve buscar uma organização escolar respaldada em relações dialógicas, que rompa com a burocracia, a centralização, com relações subordinadas/hierarquizadas e opressoras que se reproduzem dentro do espaço escolar perpetuando a chamada divisão do trabalho, em que uns pensam (os opressores) e outros executam (os oprimidos).

A gestão que tanto almejamos é aquela que contribua para formação de cidadãos e isso só acontecerá através de práticas democráticas e participativas que refletirá na qualidade da educação oferecida aos nossos alunos.

Fica mais do que evidente a importância da gestão democrática no processo de construção de uma sociedade mais justa e humanizada, onde todos podem e devem escolher seus dirigentes, acompanhar o processo de gestão, assim como, propor alternativas, mudanças e soluções para a construção de uma escola para todos, promovendo, assim, mais justiça e respeito pelo aluno, que tem por direito receber uma educação de qualidade.

\section{Referências}

BRASIL. Constituição Federal de 1988. Disponível em: $<$ https://www.planalto.gov.br/ccivil_03/constituicao/constituicaocompilado.htm/> Acesso em: 15 jun. 2016.

BRASIL. Lei no 9.394 de 20 de dezembro de 1996. Estabelece as Diretrizes e Bases da Educação Nacional (LDBEN). Disponível em: <https://www.planalto.gov.br/ccivil_03/Leis/L9394.htm> Acesso em: 10 mai. 2016. CASTRO, Alda Maria Duarte Araújo. Gerencialismo e educação: estratégias de controle e regulação da gestão escolar. In: NETO, Antônio Cabral. CASTRO, Alda Maria Duarte Araújo. FRANÇA, Magna. QUEIROZ, Maria Aparecida de. (orgs.). Pontos e contrapontos da política educacional: uma leitura contextualizada de iniciativas governamentais. Brasília: Líber Livro Editora, 2007. 
CHESNAIS, François. A Mundialização do Capital. São Paulo: Xamã, 1996.

DEMO, Pedro. Educação e qualidade. $3^{\circ}$ ed. Coleção Magistério: Formação e Trabalho Pedagógico. Campinas SP: Papirus, 1996.

FRIGOTTO, G.; CIAVATTA, M.; RAMOS, M. (Orgs.). Ensino Médio Integrado: concepções e contradições. SP: Cortez, 2005.

FRIGOTTO, Gaudêncio. Educação e a crise do capitalismo real. 6.ed. São Paulo: Cortez, 2010.

HORA, Dinair Leal da. Gestão educacional democrática. 2. ed. Campinas, SP: Editora Alínea, 2010.

LACERDA, Cecília Rosa. Projeto Político-Pedagógico: construção, pesquisa e avaliação. Fortaleza: Gráfica LCR, 2004.

LOPES, Monik de Oliveira. CASTRO, Alda Maria Duarte. Modernização Administrativa: repercussões na gestão educacional. In: CASTRO, Alda Maria Duarte Araújo. FRANÇA, Magna. (orgs.). Política Educaional: contextos e perspectivas da educação brasileira. Brasília. Liber Livro, 2012.

NETO, Antônio Cabral. RODRIGUEZ, Jorge. Reformas Educacionais na América Latina: cenários, proposições e resultados. In: NETO, Antônio Cabral. CASTRO, Alda Maria Duarte Araújo. FRANÇA, Magna. QUEIROZ, Maria Aparecida de. (orgs.). Pontos e contrapontos da política educacional: uma leitura contextualizada de iniciativas governamentais. Brasília: Líber Livro Editora, 2007.

OLIVEIRA, Ibraim Vitor de. Arqué e Telos: niilismo filosófico e crise na linguagem em Fr. Nietzsche e M. Heidegger. Editrice Pontificia Università Gregoriana. Roma, Italy: 2004.

PARO, Vitor Henrique. Administração Escolar: introdução crítica.16.ed. São Paulo, Cortez, 2010.

PARO, Vitor Henrique. Gestão democrática da escola pública. São Paulo: Editora Ática, 2005.

PARO, Vitor. Parem de preparar para o trabalho: reflexões acerca dos efeitos do neoliberalismo sobre a gestão e o papel da escola básica. Celso João et ali; orgs. Trabalho, Formação e Currículo: Para onde vai a escola. São Paulo: Xamã, 2002.

ROSAR, Maria de Fátima Félix. Existem novos paradigmas na política e na administração da educação? In: OLIVEIRA, Dalila Andrade. ROSAR, Maria de Fátima Félix (orgs.). Política e Gestão da Educação. 2.ed. Belo Horizonte: Autêntica, 2008.

SANDER, Benno. Gestão da educação na América Latina: construção e reconstrução do conhecimento. Campinas, SP: Autores Associados, 1995.

VAZ, Henrique C. de Lima. Antropologia filosófica. São Paulo: Edições Loyola, 2004.

VEIGA, IIma Passos Alencastro (org). Projeto político pedagógico da escola: Uma construção possível. 22. ed. Campinas, SP: Papirus, 2006. 